\title{
Connexin 43: a New Therapeutic Target Against Chronic Kidney Disease?
}

\author{
Niki Prakoura ${ }^{a}$ Panagiotis Kavvadas ${ }^{a}$ Christos E. Chadjichristos ${ }^{a, b}$ \\ aInstitut National de la Santé Et de la Recherche Médicale UMRS 1155, Tenon Hospital, Paris, 'borbonne \\ Université, Paris, France
}

\section{Key Words}

Chronic kidney disease $\cdot$ Inflammation $•$ Fibrosis $•$ Connexin43 $\cdot$ Targets of therapy

\begin{abstract}
Chronic kidney disease is an incurable to date pathology with a continuously growing incidence that contributes to the increase of the number of deaths worldwide. With currently no efficient prognostic or therapeutic options being available, the only possibility for treatment of end-stage renal disease is renal replacement therapy through dialysis or transplantation. Understanding the molecular mechanisms participating in the progression of renal diseases and uncovering the pathways implicated will permit the identification of novel and more efficient targets of therapy. Connexin43 was recently identified as a novel player in the development of chronic kidney disease. It was found de novo expressed and/or differentially localized in various renal cell populations during progression of renal disease, indicating an abnormal connexin signaling, both in patients and animal models. Subsequent in vivo studies demonstrated that connexin43 is involved in mediating inflammatory and fibrotic processes contributing to renal damage. Genetic, pharmaco-genetic or peptide-based inhibition of connexin43 in animal models and cell culture systems was successful in preventing the progression of the pathology and preserving the cell phenotypes. This review will summarize the recent advances on connexin43 in the field of kidney diseases and discuss the potential of future connexin43based therapies against chronic kidney disease.

\section{Introduction}

Chronic kidney disease (CKD) is a major burden of public health associated with high morbidity and mortality worldwide. The number of patients suffering from CKD is constantly growing because of aging of the population, improved survival from cardiovascular diseases, and spreading of type-2 diabetes [1]. The most common causes of CKD include diabetes mellitus followed by high blood pressure and glomerulonephritis. The remaining cases can be due to polycystic kidney disease, obstructive nephropathy, pyelonephritis and others [2]. These pathologies may affect any of the kidney structures including renal vessels, glomeruli, 
and the tubulointerstitial compartment. Despite their different origin, renal diseases share common mechanisms involving inflammatory processes and the pathological accumulation of extracellular matrix which lead to gradual impairment of renal structure and function [3, 4]. Maintenance of normal renal parenchyma and homeostasis is essential for preservation of renal function and protection from CKD $[3,4]$. Although our understanding of the mechanisms implicated in the development of renal diseases has been reinforced over the last years, there is a current lack of available early prognostic markers and therapeutic options against CKD, which necessitates the discovery of more targeted and efficient treatments $[3,4]$.

\section{Connexins}

Tissue homeostasis and structural integrity is maintained by specialized protein structures involving tight, adherens and gap junctions. Gap junctions are composed of two intercellular hemichannels, the connexons, which allow the direct communication between adjacent cells [5]. Connexons are localized on the plasma membrane of two neighboring cells and create a hydrophilic pore between the cytoplasm of the connected cells allowing the exchange of low molecular weight chemical mediators like ions ( $\mathrm{Ca} 2+, \mathrm{Na}+$, etc.) and second messenger molecules (cAMP, IP3, etc.) [6]. Apart from cell-to-cell communication, uncoupled connexons can exert the same functions as a complete gap junction, therefore allowing cell-to-matrix communication [7]. Connexons consist of six connexins forming a homo- or a heterohexamer. Connexins are named according to their predicted molecular weight; 20 connexin genes have been identified in mice and 21 in humans, sharing significant homology [8]. Besides specific exceptions like erythrocytes, thrombocytes mature skeletal muscle fibers and spermatozoids, gap junctions are present among all types of cells [9]. Gap junctions therefore provide a universal function as intercellular channels of communication that form the basis of direct cellular interactions. Given the relatively low specificity of gap junctions that allows passage of diverse molecules, it is not surprising that they are involved in a wide variety of physiological functions in different cell types including cell growth [10], glandular secretion [11], vascular homeostasis and angiogenesis [12], proliferation [13], bone development [14], cardiac morphogenesis [15, 16], glial function [17] and neuronal migration [18], stem cell development [19] and others.

Earlier studies have reported that several connexin isoforms are implicated in the renal physiopathology. Nearly half of the 20 members of the connexin family were found to be expressed throughout different renal compartments, at least at the mRNA level, including Cx26, Cx30.3, Cx31, Cx32, Cx37, Cx40, Cx43, Cx45, and Cx46 [20, 21]. However, connexin mRNA and protein expression do not always correlate and conflicting data regarding connexin expression and localisation have been reported. In this review we will mainly focus on the role of $\mathrm{Cx} 43$ in chronic renal disease.

\section{Connexin43}

Connexin43 ( $\mathrm{Cx} 43)$ is considered as the most widely expressed connexin. As is the case with other connexins, extensive studying of $\mathrm{Cx} 43$ has revealed that apart from its role in cell-to-cell communication, it can mediate gene transcription, cytoskeleton dynamics, ATP exocytosis, vesicle release and cell stress [22]. Cx43 is abundantly expressed in the heart and is indispensable for heart development and myocyte function [23]. Similarly, it is the most widely expressed connexin in the retina, but its role goes beyond cell communication since it can be part of a pathogenic pathway that leads to loss of retinal epithelium [24]. In contrast, vascular Cx43 has been shown to have a deleterious role in progression of atherosclerosis since reduction of its expression had a protective, possibly anti-inflammatory, effect in atherosclerosis susceptible mice [25]. In the brain, $\mathrm{Cx} 43$ is the main connexin in astrocytes but its exact role in neuronal physiology and neurodegeneration is disputed with contradicting 
evidence on whether it exerts a neuroprotective or deleterious role [26]. In osteoblasts and osteocytes, Cx43 hemichannels are considered necessary for cell survival [27] while it is central to spermatogenesis and testis homeostasis [28]. Finally, Cx43 is expressed in several tumor types including liver, prostate, and breast. Its role in carcinogenesis and metastasis is far from straight forward since it has been shown that Cx43 can have both pro- [29] and antimetastatic capacity in different tumors [30] which indicates a tissue or even cell-specific way of action.

\section{Connexin43 in the kidney}

Cx43 was first detected in the rat kidney in 1989 [31]. Barajas et al. provided a more complete study and concluded that $\mathrm{Cx} 43$ localizes in renal vasculature, mesangial cells and collecting ducts [32]. In 1997, Hillis et al. studied Cx43 expression in biopsies from patients with different inflammatory glomerulopathies and found it strongly expressed by infiltrating cells and suffering tubular epithelial cells, as well as de novo expressed in interstitial sites of injury [33]. Broadening the spectrum of renal pathologies involving Cx43 upregulation, a Japanese group reported the presence of $\mathrm{Cx} 43$ in normal podocytes in a linear pattern and a shift in this linear distribution in patients with diabetic nephropathy, [34] while Guo et al. reported decreased $\mathrm{Cx} 43$ in glomeruli of diabetic patients without specifying the cell types implicated [35]. In vitro data from renal epithelial cells exposed to high glucose, provided for the first time a functional explanation for $\mathrm{Cx} 43$ upregulation under stressful conditions, indicating that $\mathrm{Cx} 43$ gap junctions mediate the emission of deleterious $\mathrm{Ca}^{+2}$ signals [36]; however the exact role of $\mathrm{Cx} 43$ in the progression of renal disease remained unclear. In parallel, many studies focused on a possible role for $\mathrm{Cx} 43$ on renin secretion and regulation of blood pressure. Initial reports suggested that $\mathrm{Cx} 43$ promoted renin secretion. The replacement of $\mathrm{Cx} 43$ by $\mathrm{Cx} 32$ in transgenic mice reduced the expression and secretion of renin and prevented the renin-dependent hypertension in the 2K1C (2-kidney, 1-clip) model [37]. However, Takenaka et al. demonstrated that a specific Cx43 blocking peptide (GAP26) reduced glomerular filtration rate without altering blood pressure or renin activity, in contrast to the blockade of $\mathrm{Cx} 37$ and $\mathrm{Cx} 40$ [38]. Moreover, endothelial-specific deletion of $\mathrm{Cx} 43$ had no effect on renin secretion and blood pressure in contrast to mice deficient in Cx40 [39].

\section{Connexin43 in experimental CKD}

The above mentioned studies established the fact that $\mathrm{Cx} 43$ is expressed in the renal parenchyma and the vasculature under resting and/or pathological conditions in both animals and humans. Given its important role in cell communication and signaling it was not long before the role of $\mathrm{Cx} 43$ in renal pathology began to be investigated.

\section{Renal vasculature}

Renal vasculature is anatomically involved in many nephropathies resulting in CKD including hypertensive nephropathy, vascular stenosis, ischemic nephropathy, and vasculitis. $\mathrm{Cx} 43$ has been extensively studied in vascular pathophysiology. As reviewed elsewhere, it appears to be important for the regulation of the myogenic tone and the proliferation and migration of vascular smooth muscle cells (VSMC) [40]. In the renal vasculature Cx43 localizes, apart from VSMCs, in endothelial cells of the renal, lobar, arcuate, and interlobular arteries and afferent and efferent arterioles [41]. As mentioned above, a role for Cx43 in renin secretion and control of blood pressure has also been reported but findings are still contradicting.

To study the role of $\mathrm{Cx} 43$ in hypertensive CKD, we used a renin transgenic mouse model (RenTg) that overexpresses renin in the liver, causing a rapid increase of blood pressure and a 
slowly progressive deterioration of renal function, thus mimicking kinetics in human disease $[42,43]$. Renin overexpression gradually induced $\mathrm{Cx} 43$ which localized in peritubular and glomerular capillaries and correlated with the severity of the disease [44]. Alonso et al. have demonstrated than in aortic smooth muscle cells, angiotensin II induced Cx43 expression by driving NF- $\kappa \mathrm{B}$ binding to $\mathrm{Cx} 43$ promoter [45]. To examine the potentially functional role of $\mathrm{Cx} 43$ upregulation, we crossed RenTg mice with $\mathrm{Cx} 43$ heterozygous mice $\left(\mathrm{Cx} 43^{+/-}\right)$and monitored the effect of $\mathrm{Cx} 43$ downregulation on the progression of the disease [46]. Partial deletion of $\mathrm{Cx} 43$ had no effect on blood pressure, supporting the notion that it is not implicated in blood pressure regulation. However, it significantly reduced albuminuria, inflammatory infiltrates and interstitial fibrosis. The protection from the progression of renal disease in this model was subsequently associated to a reduced interaction between endothelial and inflammatory cells. Incubation of endothelial cells with $\mathrm{Cx} 43$ blocking peptides reduced monocyte adhesion to the endothelial layer. Pre-incubation of monocytes with the same blocker yielded similar decreased adhesive capacity of monocytes on the endothelium. ATP release, an activator of purinergic cell membrane receptors, has been reported as a means of crosstalk between infiltrating cells and activated endothelium [47], generating pro-inflammatory signals and upregulation of monocytes adhesion molecules [48]. Cx43 has been described to mediate ATP release in several systems including neutrophils [47], microglia [49], retinal pigment epithelial cells [50], inflammatory cells [51] and proximal tubular epithelial cells [52]. Upregulation of Cx43 in renal endothelial cells could promote CKD by generating a pro-inflammatory environment that promotes leukocyte adhesion and infiltration through activation of purinergic signaling.

The podocyte

Yaoita et al. were the first to demonstrate that $\mathrm{Cx} 43$ is upregulated in experimental models of glomerular renal disease. Using the puromycin aminonucleoside (PAN) nephrosis model in rats, they showed that injured podocytes strongly expressed Cx43 while its expression in mesangial and glomerular endothelial cells remained unchanged [53]. Even though they provided no evidence for the role of $\mathrm{Cx} 43$ in podocyte pathology, they were the first to support the idea that although in basal conditions there are no gap junctions between podocytes, accumulation of $\mathrm{Cx} 43$ in podocytes under pathological conditions could indicate the formation of communication channels between neighboring cells. After this report, it was only nine years later when $\mathrm{Cx} 43$ was reintroduced in experimental nephropathy. In 2011, our group published a study on the expression of $\mathrm{Cx} 43$ in different models of CKD. Among other findings, we showed that in the model of nephrotoxic serum-induced glomerulonephritis (NTS-GN) in mice, Cx43 was strongly upregulated in suffering glomeruli [44]. A year later, an in vitro study on murine podocytes exposed to PAN pointed towards a deleterious role of Cx43 in injured podocytes [54]. Treatment of cultured podocytes with PAN induced Cx43 mRNA and protein expression and increased ROS production via NADPH activation. Gap junctions' inhibitors reduced caspace- 3 activation and restored cell viability, indicating that newly formed gap junctions and/or hemichannels propagate pro-apoptotic signals in response to stress. Similar results were reported with an in vitro system of aldosteroneinduced podocyte damage [55]. Aldosterone treatment increased Cx43 expression and gap junction formation and promoted podocyte apoptosis. SiRNA against Cx43 reversed ROS production and restored BAX/BCL-2 ratio, indicating that cell stress signals result in cell death via $\mathrm{Cx} 43$-mediated signaling.

Despite the increasing in vitro evidence for the role of $\mathrm{Cx} 43$ in podocyte pathophysiology, its in vivo importance for the progression of CKD had not yet been demonstrated. We studied $\mathrm{Cx} 43$ expression in biopsies from patients suffering from different types of GN including IgA and C3-GN and found a strong upregulation of Cx43 in the glomerulus [56]. To investigate whether this upregulation is related to the progression of the disease, we used the $\mathrm{Cx} 43^{+/}$ mice in the NTS-GN model of CKD. Cx43 was strongly upregulated from early on in the progression of the disease and was de novo expressed by suffering podocytes [56]. Chromatin immunoprecipitation assays revealed that $\mathrm{Cx} 43$ upregulation was mediated by c-Jun and

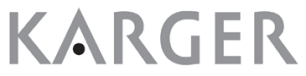


STAT1 binding on $\mathrm{Cx} 43$ promoter but not by NF- $\mathrm{BB}$ as previously reported in challenged arteries [45]. $\mathrm{Cx} 43^{+/-}$mice showed more preserved renal function and glomerular structure vs. wild type mice, accompanied by less podocyte apoptosis, inflammatory infiltrates and fibrosis [56]. Mechanistically, we were able to demonstrate in vitro that $\mathrm{Cx} 43$ signaling was not restricted to promoting apoptosis. TGF- $\beta$ induced phenotypic changes to cultured podocytes associated with increased expression of mesenchymal and migratory markers. Blockade of either $\mathrm{Cx} 43$ or purinergic signaling resulted in similar reversal of TGF- $\beta$-induced alterations, directing towards a cross-talk between ATP signaling and $\mathrm{Cx} 43$ deleterious actions [56]. Podocytes express a wide range of purinergic receptors including $\mathrm{P}_{2} \mathrm{Y}_{2}$ and $\mathrm{P} 2 \mathrm{X}_{7}$ among others. Extracellular ATP binds to purinergic receptors activating release of $\mathrm{Ca}^{+2}$ from intracellular stores leading to podocyte depolarization [57]. In vivo imaging studies have demonstrated that propagation of $\mathrm{Ca}^{+2}$ waves occurs through gap junctions and mediates several pathogenic responses in the glomerulus including contraction of the glomerular tuft, increased capillary albumin permeability and acquisition of a migratory phenotype of podocytes [58].

Cx43 upregulation in stressed podocytes appears to be stimuli-independent. PAN and aldosterone mediate podocyte toxicity, while the NTS model induces inflammation and altered renal hemodynamics. In a recent study in rats suffering from obesity-related glomerulopathy, Zhao et al. demonstrated increased Cx43 expression that paralleled renal inflammation [59], while increased glomerular, probably podocyte expression of $\mathrm{Cx} 43$ has also been reported in a rat model of type-2 diabetes [60]. On the contrary, another study on type 2 diabetes and overt nephropathy patients has correlated the downregulation and redistribution of Cx43 expression in biopsies to the decline of renal function [61]. Conclusively, existing data indicate that the deleterious role of $\mathrm{Cx} 43$ in CKD may exceed its pro-inflammatory and proapoptotic actions. De novo expression and/or redistribution of $\mathrm{Cx} 43$ by suffering cells may induce responses to pathogenic stimuli and phenotypic alterations that are not yet fully understood and promote the disease in different ways.

\section{Mesangial cells}

Mesangial cells are contractile cells of the glomerulus that are in contact with other mesangial or endothelial cells via gap junctions [62]. They are considered of great importance since they maintain the glomerular structure by supporting glomerular capillaries and podocytes and regulating glomerular matrix turnover [63]. Mesangioproliferative GN, especially IgA, and diabetic nephropathy are the main types of CKD related to mesangial cells.

Using the anti-Thy 1.1 model of GN in rats, Morioka et al. demonstrated a differential regulation of $\mathrm{Cx} 43$ in mesangial cells vs. podocytes. While the podocyte expression of $\mathrm{Cx} 43$ increased in animals with GN, it decreased in mesangial cells, showing that $\mathrm{Cx} 43$ upregulation is not a universal response to injury in all renal cell populations [64]. In agreement with this study, exposure of cultured mesangial cells to high glucose [65] or aldosterone [66] decreased the expression of $\mathrm{Cx} 43$ and induced cytoskeletal rearrangements and proliferation, respectively. The effect of $\mathrm{Cx} 43$ on mesangial proliferation, one of the basic histological findings in IgA nephropathy, was attributed to the function of $\mathrm{Cx} 43$ hemichannels, since aldosterone had no effect on gap junction formation. Transient overexpression of $\mathrm{Cx} 43$ abolished the proproliferating effect of aldosterone possibly via $\mathrm{Ca}^{+2} /$ Protein kinase C-related signaling [66]. Treatment of mesangial cells with high glucose, a commonly used in vitro model to mimic diabetic nephropathy, resulted in RhoA/ROCK-mediated cytoskeletal rearrangements, translocation of NF- $\mathrm{KB}$ to the nucleus, F-actin accumulation and an enhanced interaction between zonula occludens-1 (ZO-1) and Cx43. Interestingly, $\mathrm{Cx} 43$ overexpression reversed NF- $\kappa B$ nuclear translocation, while ZO-1 depletion or disruption of F-actin formation prevented the reduction of $\mathrm{Cx} 43$ levels induced by high glucose [65]. This indicated the existence of a complex relationship between mesangial cytoskeletal proteins and NF- $\kappa \mathrm{B}$ that cross-talks with $\mathrm{Cx} 43$ signaling. Collectively, the above studies in mesangial cells argue for a protective role of $\mathrm{Cx} 43$ in these cells, which could be exploited in regards of diabetic and

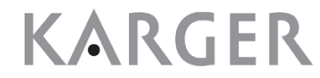




\section{Cellular Physiology Cell Physiol Biochem 2018;49:998-1009 and Biochemistry $\begin{aligned} & \text { DOI: 10.1159/000493230 } \\ & \text { Published } 02018 \text { The Author(s). Published by S. Karger AG, Basel }\end{aligned}$ \\ Prakoura et al.: $\mathrm{C} \times 43$ in CKD}

IgA nephropathy where the mesangium is of primary importance. In contrast, Solini et al. have shown that changes in extracellular ATP levels, known to be controlled by the function of $\mathrm{Cx} 43$, regulate mesangial matrix expansion via a TGF- $\beta$-P2X7 pathway [67]. Further in vivo studies employing the appropriate experimental nephropathy models combined with systemic or conditional manipulation of $\mathrm{Cx} 43$ expression seem to be necessary to definitely uncover the functional role of $\mathrm{Cx} 43$ in mesangial cell-related CKD.

\section{Tubular epithelium}

Renal tubular epithelial cells are the primary or secondary target in many forms of CKD. Obstructive nephropathy and renal ischemia have a direct impact on the renal epithelium while diabetic nephropathy, hypertensive nephropathy and GN progressively impair tubules as a secondary effect. After Guo et al. reported the expression of $\mathrm{Cx} 43$ in tubular segments [68], a number of in vitro studies suggested a possible role for gap junctions/hemichannels in mediating pathological signaling in tubular epithelial cells. In renal ischemia, epithelial cells are the main cell type susceptible to damage. $\mathrm{O}_{2}$ depletion reduces intracellular ATP levels

Table 1. Physiopathological functions of $\mathrm{Cx} 43$ in different in vitro and in vivo models of renal disease

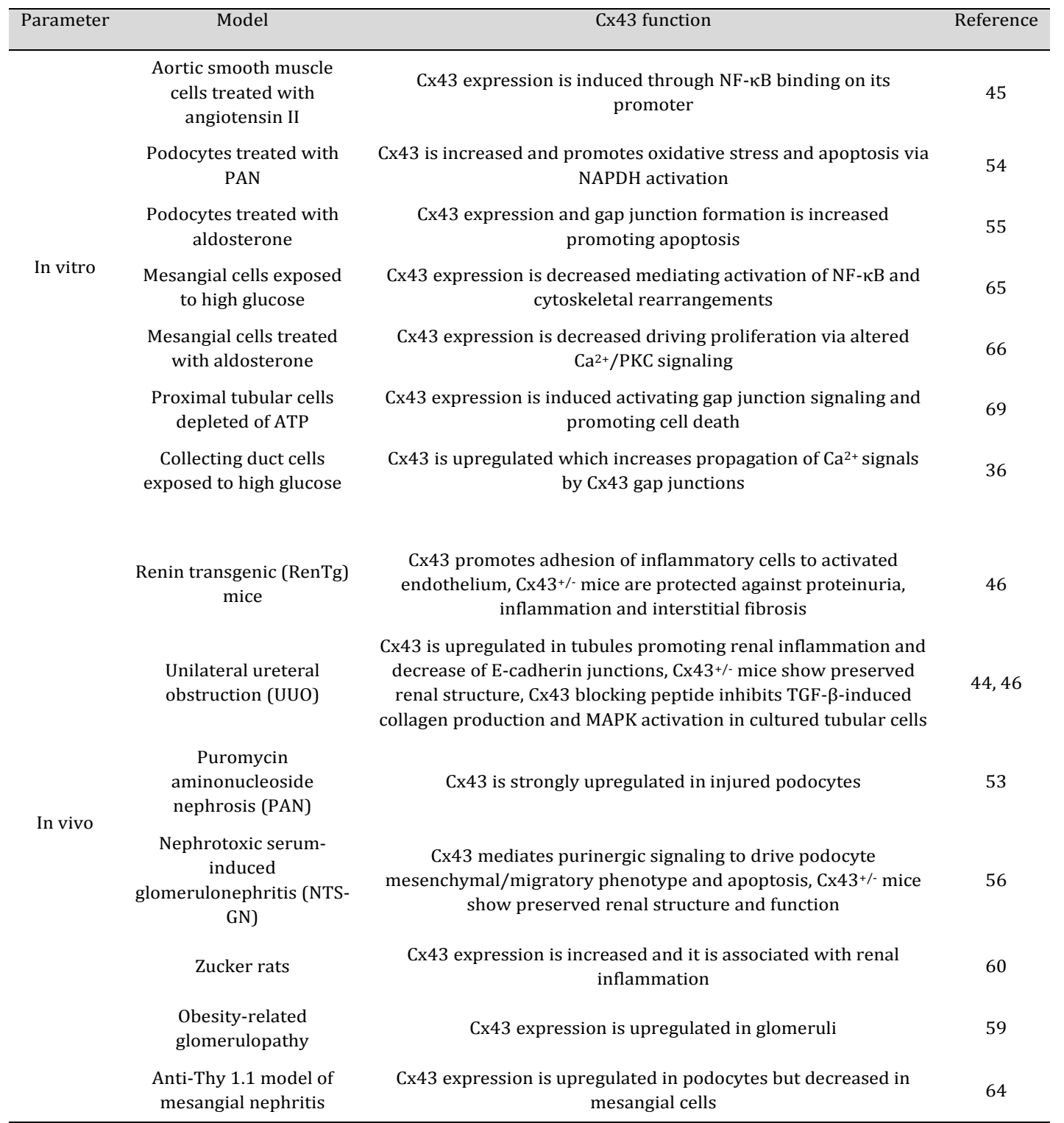


which in turn results in tubular necrosis. Taking into account that $\mathrm{Cx} 43$ hemichannels had been related with ATP release, Vergara et al. investigated the role of $\mathrm{Cx} 43$ in an in vitro model of ATP depletion in human proximal tubular cells [69]. ATP depletion induced Cx43 mRNA and protein expression and activated hemichannel signaling. This was also accompanied by increased cell death, but no connection between the two effects was demonstrated. Another study in tubular epithelial cells demonstrated an increase of $\mathrm{Cx} 43$ expression induced by TGF- $\beta 1$, which triggered hemichannel function and provoked ATP release that was further linked to increased expression of interleukin 6 and fibronectin [52]. In diabetic nephropathy, secondary hypertension develops in response to chronic exposure to increased glucose concentrations. When exposed to high glucose in vitro, human collecting ducts responded by upregulation of $\mathrm{Cx} 43$ and increased $\mathrm{Ca}^{+2}$ signals propagation mediated by $\mathrm{Cx} 43$ gap junctions [36].

To study expression and localization of $\mathrm{Cx} 43$ in a model of tubular disease in vivo, we used the well-established model of unilateral ureteral obstructive nephropathy (UUO) in mice [44]. Cx43 was barely detected in control tubular cells but after UUO it was strongly expressed in tubules of both cortex and medulla. $\mathrm{Cx} 43^{+/-}$mice showed reduced expression of leukocytes adhesion molecules and reduced macrophage infiltration. Pursuing these initial findings, we demonstrated that blocking Cx43 with antisense oligonucleotides blunted the inflammatory response in UUO and partially preserved E-cadherin junctions in tubular cells in vivo [46]. In subsequent in vitro studies, activation of tubular cells with TGF- $\beta$ induced collagen production, mitogen-activated protein kinases (MAPKs) phosphorylation and expression of Sp1, a pro-fibrotic transcription factor that promotes collagen synthesis [70]. Blocking Cx43 with the GAP26 peptide blocker reduced the TGF- $\beta$ effects, indicating that second messengers acting via $\mathrm{Cx} 43$ signaling are important for the establishment of renal fibrosis. Table 1 summarizes the current understanding of the role of $\mathrm{Cx} 43$ in renal diseases.

\section{Connexin43 as a therapeutic target against CKD}

Over the last years, a great effort has been made towards the discovery of novel and more efficient pharmacological targets to treat renal diseases. Cx43 has emerged as an active player in the progression of CKD, whose inhibition was proven to successfully impede the development of renal disease by arresting the progress of several inflammatory and fibrotic processes. We were among the first to show that $\mathrm{Cx} 43$ is upregulated and participates in the progression of renal disease in several animal models of CKD. Moreover, by using $\mathrm{Cx} 43^{+/}$ mice we demonstrated that a reduced expression of $\mathrm{Cx} 43$ was sufficient to confer protection against hypertensive nephropathy, obstructive nephropathy and GN $[46,56]$.

Targeted therapeutic approaches to prevent $\mathrm{Cx} 43$ signaling involve the use of antisense oligonucleotides (AS-ODNs) and connexin mimetic peptides designed to mimic sequences on extracellular or intracellular loops of connexin proteins. The inhibition of $\mathrm{Cx} 43$ by ASODNs has been shown to dampen inflammatory responses and promote wound-healing in many tissues including central nervous system [71], skin [72-74], skeletal muscle [75], heart [76], smooth muscle [77, 78] and vascular endothelium [79-81]. Moreover, there are clinical trials using topical application of a gel containing Cx43 AS-ODNs, which have shown a safe and tolerable treatment of skin wounds, venous leg ulcers and diabetic foot ulcers [71]. In our studies, the use of AS-ODNs against Cx43 inhibited renal inflammation and fibrosis and efficiently preserved renal function in animal models of CKD [46, 56]. Notably, in all cases administration of AS-ODNs started as a therapeutic approach after establishment of the disease, which highlights the potency of $\mathrm{Cx} 43$ inhibition in the protection against development of renal disease.

Connexin mimetic peptides may function by either blocking the hemichannel opening or the gap junction formation, based on the protein site (intracellular or extracellular) where the peptides are designed to bind. These specific connexin blockers have been preferred the last years in cell culture and animal studies in place of classical global gap junction 
inhibitors, since their targeted action is more likely to restrict the unwanted effects on physiological functions and establish an effective regulation. The $\mathrm{Cx} 43$ mimetic peptides GAP19 (hemichannel blocker) and GAP26 (gap junction blocker) were proven efficient in preventing arrhythmogenesis and death in a genetic mouse model of muscular dystrophy [82], while administration of GAP26 reduced the myocardial infarct size and improved survival of isolated cardiomyocytes in a rat model of myocardial infarction [83]. In another study, Cx43 mimetic peptides significantly reduced swelling, astrocyte proliferation and neuronal loss in a rodent ex vivo model of spinal cord injury [84]. Furthermore, recent promising studies have been reported in mice suffering from myocardial ischemia where Cx43 hemichannels have been selectively inhibited with GAP19 [85]. We have recently demonstrated that blocking Cx43 with the GAP26 peptide in vitro prevented cell responses associated to inflammatory and fibrotic pathways, i.e. it inhibited monocyte adhesion in activated endothelium, it hampered TGF- $\beta$-induced responses in tubular cells [46] and it prevented cytoskeletal changes and apoptosis in podocytes [56]. It remains to be established whether $\mathrm{Cx} 43$ mimetic peptides can protect against the progression of renal disease in vivo in animal models.

\section{Conclusion and perspectives}

CKD reached pandemic proportions and is one of the major causes of death worldwide. Even though significant progress has been made over the last years, our understanding of the complex mechanisms driving the progression of renal disease is still incomplete. Therapeutic interventions are insufficient and especially in advanced stages the only therapeutic option is dialysis or transplantation. $\mathrm{Cx} 43$ was recently identified as a novel mediator of renal disease involved in central processes of inflammation and fibrosis, while its inhibition even after the initiation of the disease was capable to attenuate renal damage and preserve renal function in animal models of vascular, tubular and glomerular CKD. In this sense, novel therapies based on the targeted blockade of $\mathrm{Cx} 43$ in desirable cell populations may constitute a future option for efficient inhibition of the progression of CKD. Taking into account that targeted blockers of $\mathrm{Cx} 43$ are already available, it remains to be investigated whether they exert a protective effect in preclinical models of CKD, with a potential future application into clinical practice.

\section{Disclosure Statement}

The authors declare to have no competing interests.

\section{References}

1 Hill NR, Fatoba ST, Oke JL, Hirst JA, O'Callaghan CA, Lasserson DS, Hobbs R: Global Prevalence of Chronic Kidney Disease - A Systematic Review and Meta-Analysis. Plos One 2016;11:e0158765.

-2 GBD 2015 Disease and Injury Incidence and Prevalence Collaborators: Global, regional, and national incidence, prevalence, and years lived with disability for 310 diseases and injuries, 1990-2015: a systematic analysis for the Global Burden of Disease Study 2015. Lancet 2016;388:1545-1602.

3 Harris RC, Neilson EG: Toward a unified theory of renal progression. Annu Rev Med 2006;57:365-380.

4 López-Novoa JM, Martínez-Salgado C, Rodríguez-Peña AB, López-Hernández FJ: Common pathophysiological mechanisms of chronic kidney disease: therapeutic perspectives. Pharmacol Ther 2010 Oct;128:61-81.

5 Bosco D, Haefliger JA, Meda P: Connexins: key mediators of endocrine function. Physiol Rev 2011;91:13931445. 


\section{Cellular Physiology Cell Physiol Biochem 2018;49:998-1009 and Biochemistry DOI: 10.1159/000493230 20102018 The Author(s). Published by S. Karger AG, Basel \\ Prakoura et al.: Cx43 in CKD}

6 Spray DC, Stern JH, Harris AL, Bennett MV: Gap junctional conductance: comparison of sensitivities to H and Caions. Proc Natl Acad Sci 1982;79:441-445.

7 Zhou JZ, Jiang JX: Gap junction and hemichannel-independent actions of connexins on cell and tissue functions-an update. FEBS Lett 2014;588:1186-1192.

$>8$ Wagner C: Function of connexins in the renal circulation. Kidney Int 2008;73:547-555.

-9 Willecke K, Eiberger J, Degen J, Eckardt D, Romualdi A, Güldenagel M, Deutsch U, Söhl G: Structural and functional diversity of connexin genes in the mouse and human genome. Biol Chem 2002;383:725-737.

$\$ 10$ Loewenstein WR, Rose B: The cell-cell channel in the control of growth. Semin Cell Biol 1992;3:59-79.

11 Meda P, Chanson M, Pepper M, Giordano E, Bosco D, Traub O, Willecke K, el Aoumari A, Gros D, Beyer EC, et al: In vivo modulation of connexin 43 gene expression and junctional coupling of pancreatic $\beta$-cells. Exp Cell Res 1991;192:469-480.

12 Wallez Y, Huber P: Endothelial adherens and tight junctions in vascular homeostasis, inflammation and angiogenesis. Biochim Biophys Acta 2008;1778:794-809.

13 Vinken M, Decrock E, De Vuyst E, Ponsaerts R, D’hondt C, Bultynck G, Ceelen L, Vanhaecke T, Leybaert L, Rogiers V: Connexins: sensors and regulators of cell cycling. Biochim Biophys Acta 2011;1815:13-25.

14 Batra N, Kar R, Jiang JX: Gap junctions and hemichannels in signal transmission, function and development of bone. Biochim Biophys Acta 2012;1818:1909-1918.

15 Reaume AG, de Sousa PA, Kulkarni S, Langille BL, Zhu D, Davies TC, Juneja SC, Kidder GM, Rossant J: Cardiac malformation in neonatal mice lacking connexin43. Science 1995;267:1831-1834.

16 Krüger O, Maxeiner S, Kim JS, Van Rijen HV, de Bakker JM, Eckardt D, Tiemann K, Lewalter T, Ghanem A, Lüderitz B, Willecke K: Cardiac morphogenetic defects and conduction abnormalities in mice homozygously deficient for connexin40 and heterozygously deficient for connexin45. J Mol Cell Cardiol 2006;41:787-797.

17 Naus CC, Bani-Yaghoub M, Rushlow W, Bechberger JF: Consequences of impaired gap junctional communication in glial cells. Adv Exp Med Biol 1999;468:373-381.

-18 Fushiki S, Perez Velazquez JL, Zhang L, Bechberger JF, Carlen PL, Naus CC: Changes in neuronal migration in neocortex of connexin 43 null mutant mice. J Neuropathol Exp Neurol 2003;62:304-314.

19 Kar R, Batra N, Riquelme MA, Jiang JX: Biological role of connexin intercellular channels and hemichannels. Arch Biochem Biophys 2012;524:2-15.

20 Hanner F, Sorensen CM, Holstein-Rathlou NH, Peti-Peterdi J: Connexins and the kidney. Am J Physiol Regul Integr Comp Physiol 2010;298:R1143-1155.

21 Hills CE, Price GW, Squires PE: Mind the gap: connexins and cell-cell communication in the diabetic kidney. Diabetologia 2015;58:233-241.

22 Ribeiro-Rodrigues TM, Martins-Marques T, Morel S, Kwak BR, Girão H: Role of connexin 43 in different forms of intercellular communication - gap junctions, extracellular vesicles and tunnelling nanotubes. J Cell Sci 2017;130:3619-3630.

23 Oyamada M, Kimura H, Oyamada Y, Miyamoto A, Ohshika H, Mori M: The expression, phosphorylation, and localization of connexin 43 and gap-junctional intercellular communication during the establishment of a synchronized contraction of cultured neonatal rat cardiac myocytes. Exp Cell Res 1994;212:351-358.

-24 Danesh-Meyer HV, Zhang J, Acosta ML, Rupenthal ID, Green CR: Connexin43 in retinal injury and disease. Prog Retin Eye Res 2016;51:41-68.

25 Kwak BR, Veillard N, Pelli G, Mulhaupt F, James RW, Chanson M, Mach F: Reduced connexin43 expression inhibits atherosclerotic lesion formation in low-density lipoprotein receptor-deficient mice. Circulation 2003;107:1033-1039.

26 Freitas-Andrade M, Naus CC: Astrocytes in neuroprotection and neurodegeneration: The role of connexin43 and pannexin1. Neuroscience 2016;323:207-221.

27 Plotkin LI: Connexin 43 hemichannels and intracellular signaling in bone cells. Front Physiol 2014 4;5:131.

28 Chevallier D, Carette D, Segretain D, Gilleron J, Pointis G: Connexin 43 a check-point component of cell proliferation implicated in a wide range of human testis diseases. Cell Mol Life Sci 2013;70:1207-1220.

29 Elzarrad MK, Haroon A, Willecke K, Dobrowolski R, Gillespie MN, Al-Mehdi AB: Connexin-43 upregulation in micrometastases and tumor vasculature and its role in tumor cell attachment to pulmonary endothelium. BMC Med 2008;6:20.

30 Li Z, Zhou Z, Welch DR, Donahue HJ: Expressing connexin 43 in breast cancer cells reduces their metastasis to lungs. Clin Exp Metastasis 2008;25:893-901. 


\section{Cellular Physiology Cell Physiol Biochem 2018;49:998-1009

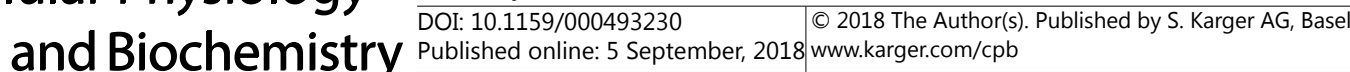 \\ Prakoura et al.: Cx43 in CKD}

-31 Beyer EC, Kistler J, Paul DL, Goodenough DA: Antisera Directed against Connexin43 Peptides React witha 43-kD Protein Localized to Gap Junctions in Myocardium and Other Tissues. J Cell Biol 1989;108:595-605.

-32 Barajas L, Liu L, Tucker M: Localization of connexin43 in rat kidney. Kidney Int 1994;46:621-626.

-33 Hillis GS, Duthie LA, Brown PA, Simpson JG, MacLeod AM, Haites NE: Upregulation and co-localization of connexin43 and cellular adhesion molecules in inflammatory renal disease. J Pathol 1997;182:373-379.

34 Sawai K, Mukoyama M, Mori K, Yokoi H, Koshikawa M, Yoshioka T, Takeda R, Sugawara A, Kuwahara T, Saleem MA, Ogawa 0, Nakao K: Redistribution of connexin43 expression in glomerular podocytes predicts poor renal prognosis in patients with type 2 diabetes and overt nephropathy. Nephrol Dial Transplant 2006;21:2472-2477.

35 Guo YN, Wang JC, Cai GY, Hu X, Cui SY, Lv Y, Yin Z, Fu B, Hong Q, Chen XM: AMPK-mediated downregulation of connexin 43 and premature senescence of mesangial cells under high-glucose conditions. Exp Gerontol 2014;51:71-81.

-36 Hills CE, Bland R, Wheelans DC, Bennett J, Ronco PM, Squires PE: Glucose-evoked alterations in connexin43-mediated cell-to-cell communication in human collecting duct: a possible role in diabetic nephropathy. Am J Physiol Renal Physiol 2006;291:F1045-1051.

37 Haefliger JA, Krattinger N, Martin D, Pedrazzini T, Capponi A, Döring B, Plum A, Charollais A, Willecke K, Meda P: Connexin43-dependent mechanism modulates renin secretion and hypertension. J Clin Invest 2006;116:405-413.

38 Takenaka T, Inoue T, Kanno Y, Okada H, Meaney KR, Hill CE, Suzuki H: Expression and role of connexins in the rat renal vasculature. Kidney Int 2008;73:415-422.

-39 Theis M, de Wit C, Schlaeger TM, Eckardt D, Krüger O, Döring B, Risau W, Deutsch U, Pohl U, Willecke $\mathrm{K}$ : Endothelium-specific replacement of the connexin43 coding region by a lacZ reporter gene. Genesis 2001;29:1-13.

$>40$ Figueroa XF, Duling BR: Gap junctions in the control of vascular function. Antioxid Redox Signal 2009;11:251-266.

-41 Zhang J, Hill CE: Differential connexin expression in preglomerular and postglomerular vasculature: accentuation during diabetes. Kidney Int 2005;68:1171-1185.

$\checkmark 42$ Caron KM, James LR, Kim HS, Morham SG, Sequeira Lopez ML, Gomez RA, Reudelhuber TL, Smithies O: A genetically clamped renin transgene for the induction of hypertension. Proc Natl Acad Sci 2002;99:82488252.

43 Huby AC, Kavvadas P, Alfieri C, Abed A, Toubas J, Rastaldi MP, Dussaule JC, Chatziantoniou C, Chadjichristos CE: The RenTg mice: a powerful tool to study renin-dependent chronic kidney disease. PLoS One 2012;7:e52362.

44 Toubas J, Beck S, Pageaud AL, Huby AC, Mael-Ainin M, Dussaule JC, Chatziantoniou C, Chadjichristos CE: Alteration of connexin expression is an early signal for chronic kidney disease. Am J Physiol Renal Physiol 2011;301:F24-32.

45 Alonso F, Krattinger N, Mazzolai L, Simon A, Waeber G, Meda P, Haefliger JA: An angiotensin II- and NFkappaB-dependent mechanism increases connexin 43 in murine arteries targeted by renin-dependent hypertension. Cardiovasc Res 2010;87:166-176.

\46 Abed A, Toubas J, Kavvadas P, Authier F, Cathelin D, Alfieri C, Boffa JJ, Dussaule JC, Chatziantoniou C, Chadjichristos CE: Targeting connexin 43 protects against the progression of experimental chronic kidney disease in mice. Kidney Int 2014;86:768-779.

-47 Eltzschig HK, Eckle T, Mager A, Küper N, Karcher C, Weissmüller T, Boengler K, Schulz R, Robson SC, Colgan SP: ATP release from activated neutrophils occurs via connexin 43 and modulates adenosine-dependent endothelial cell function. Circ Res 2006;99:1100-1108.

48 Salmi M, Jalkanen S: Cell-surface enzymes in control of leukocyte trafficking. Nat Rev Immunol 2005;5:760-771.

49 Ma Y, Cao W, Wang L, Jiang J, Nie H, Wang B, Wei X, Ying W: Basal CD38/cyclic ADP-ribose-dependent signaling mediates ATP release and survival of microglia by modulating connexin 43 hemichannels. Glia 2014;62:943-955.

50 Mugisho 00, Green CR, Kho DT, Zhang J, Graham ES, Acosta ML, Rupenthal ID: The inflammasome pathway is amplified and perpetuated in an autocrine manner through connexin43 hemichannel mediated ATP release. Biochim Biophys Acta 2018;1862:385-393. 


\section{Cellular Physiology Cell Physiol Biochem 2018;49:998-1009 and Biochemistry DOI: 10.1159/000493230 202018 The Author(s). Published by S. Karger AG, Basel \\ Prakoura et al.: Cx43 in CKD}

-51 Dosch M, Gerber J, Jebbawi F, Beldi G. Mechanisms of ATP Release by Inflammatory Cells. Int J Mol Sci 2018;19:E1222.

-52 Hills C, Price GW, Wall MJ, Kaufmann TJ, Chi-Wai Tang S, Yiu WH, Squires PE: Transforming Growth Factor Beta 1 Drives a Switch in Connexin Mediated Cell-to-Cell Communication in Tubular Cells of the Diabetic Kidney. Cell Physiol Biochem 2018;45:2369-2388.

53 Yaoita E, Yao J, Yoshida Y, Morioka T, Nameta M, Takata T, Kamiie J, Fujinaka H, Oite T, Yamamoto T: Upregulation of connexin43 in glomerular podocytes in response to injury. Am J Pathol 2002;161:1597-1606.

54 Yan Q, Gao K, Chi Y, Li K, Zhu Y, Wan Y, Sun W, Matsue H, Kitamura M, Yao J: NADPH oxidase-mediated upregulation of connexin43 contributes to podocyte injury. Free Radic Biol Med 2012;53:1286-1297.

55 Yang M, Wang B, Li M, Jiang B: Connexin 43 is involved in aldosterone-induced podocyte injury. Cell Physiol Biochem 2014;34:1652-1662.

56 Kavvadas P, Abed A, Poulain C, Authier F, Labéjof LP, Calmont A, Afieri C, Prakoura N, Dussaule JC, Chatziantoniou C, Chadjichristos CE: Decreased Expression of Connexin 43 Blunts the Progression of Experimental GN. J Am Soc Nephrol 2017;28:2915-2930.

57 Fischer KG, Saueressig U, Jacobshagen C, Wichelmann A, Pavenstädt H: Extracellular nucleotides regulate cellular functions of podocytes in culture. Am J Physiol Renal Physiol 2001;281:F1075-1081.

58 Burford JL, Villanueva K, Lam L, Riquier-Brison A, Hackl MJ, Pippin J, Shankland SJ, Peti-Peterdi J: Intravital imaging of podocyte calcium in glomerular injury and disease. J Clin Invest 2014;124:2050-2058.

59 Zhao Y, Li G, Wang Y, Liu Z: Alteration of Connexin43 expression in a rat model of obesity-related glomerulopathy. Exp Mol Pathol 2017;104:12-18.

60 Takenaka T, Inoue T, Okada H, Ohno Y, Miyazaki T, Chaston DJ, Hill CE, Suzuki H: Altered gap junctional communication and renal haemodynamics in Zucker fatty rat model of type 2 diabetes. Diabetologia 2011;54:2192-2201.

61 Sawai K, Mukoyama M, Mori K, Yokoi H, Koshikawa M, Yoshioka T, Takeda R, Sugawara A, Kuwahara T, Saleem MA, Ogawa 0, Nakao K: Redistribution of connexin43 expression in glomerular podocytes predicts poor renal prognosis in patients with type 2 diabetes and overt nephropathy. Nephrol Dial Transplant 2006;21:2472-2477.

62 Hirschi KK, Burt JM, Hirschi KD, Dai C: Gap junction communication mediates transforming growth factorbeta activation and endothelial-induced mural cell differentiation. Circ Res 2003;93:429-437.

63 Schlöndorff D, Banas B: The mesangial cell revisited: no cell is an island. J Am Soc Nephrol 2009;20:11791187.

64 Morioka T, Okada S, Nameta M, Kamal F, Yanakieva-Georgieva NT, Yao J, Sato A, Piao H, Oite T: Glomerular expression of connexin 40 and connexin 43 in rat experimental glomerulonephritis. Clin Exp Nephrol 2013;17:191-204.

65 Xie X, Chen C, Huang K, Wang S, Hao J, Huang J, Huang H: RhoA/rho kinase signaling reduces connexin43 expression in high glucose-treated glomerular mesangial cells with zonula occludens-1 involvement. Exp Cell Res 2014;327:276-286.

66 Zhang A, Han Y, Wang B, Li S, Gan W: Beyond Gap Junction Channel Function: the Expression of Cx43 Contributes to Aldosterone-Induced Mesangial Cell Proliferation via the ERK1/2 and PKC Pathways. Cell Physiol Biochem 2015;36:1210-1222.

67 Solini A, Iacobini C, Ricci C, Chiozzi P, Amadio L, Pricci F, Di Mario U, Di Virgilio F, Pugliese G. Purinergic modulation of mesangial extracellular matrix production: role in diabetic and other glomerular diseases. Kidney Int 2005;67:875-885.

68 Guo R, Liu L, Barajas L: RT-PCR study of the distribution of connexin 43 mRNA in the glomerulus and renal tubular segments. Am J Physiol 1998;275:R439-447.

69 Vergara L, Bao X, Bello-Reuss E, Reuss L: Do connexin 43 gap-junctional hemichannels activate and cause cell damage during ATP depletion of renal-tubule cells? Acta Physiol Scand 2003;179:33-38.

70 Ghayor C, Chadjichristos C, Herrouin JF, Ala-Kokko L, Suske G, Pujol JP, Galera P: Sp3 represses the Sp1mediated transactivation of the human COL2A1 gene in primary and de-differentiated chondrocytes. J Biol Chem 2001;276:36881-36895.

71 Tonkin RS, Mao Y, O'Carroll SJ, Nicholson LF, Green CR, Gorrie CA, Moalem-Taylor G: Gap junction proteins and their role in spinal cord injury. Front Mol Neurosci 2015;7:102.

72 Becker DL, Thrasivoulou C, Phillips AR: Connexins in wound healing; perspectives in diabetic patients. Biochim Biophys Acta 2012;1818:2068-2075. 


\section{Cellular Physiology Cell Physiol Biochem 2018:49:998-1009 and Biochemistry Published 10 / \\ Prakoura et al.: Cx43 in CKD}

73 Coutinho P, Qiu C, Frank S, Tamber K, Becker D: Dynamic changes in connexin expression correlate with key events in the wound healing process. Cell Biol Int 2003;27:525-541.

74 Qiu C, Coutinho P, Frank S, Franke S, Law LY, Martin P, Green CR, Becker DL: Targeting connexin43 expression accelerates the rate of wound repair. Curr Biol 2003;13:1697-1703.

75 Gorbe A, Becker DL, Dux L, Krenacs L, Krenacs T: In differentiating prefusion myoblasts connexin43 gap junction coupling is upregulated before myoblast alignment then reduced in post-mitotic cells. Histochem Cell Biol 2006;125:705-716.

76 Yasui K, Kada K, Hojo M, Lee JK, Kamiya K, Toyama J, Opthof T, Kodama I: Cell-to-cell interaction prevents cell death in cultured neonatal rat ventricular myocytes. Cardiovasc Res 2000;48:68-76.

-77 Liao Y, Duling BR: Blockade of connexin 43 expression by stable transfection of antisense cDNA in cultured vascular smooth muscle cells. Antisense Nucleic Acid Drug Dev 2000;10:275-281.

78 Yeh HI, Lupu F, Dupont E, Severs NJ: Upregulation of connexin43 gap junctions between smooth muscle cells after balloon catheter injury in the rat carotid artery. Arterioscler Thromb Vasc Biol 1997;17:31743184 .

79 Kwak BR, Pepper MS, Gros DB, Meda P: Inhibition of endothelial wound repair by dominant negative connexin inhibitors. Mol Biol Cell 2001;12:831-845.

80 Ormonde S, Chou CY, Goold L, Petsoglou C, Al-Taie R, Sherwin T, McGhee CN, Green CR: Regulation of connexin43 gap junction protein triggers vascular recovery and healing in human ocular persistent epithelial defect wounds. J Membr Biol 2012;245:381-388.

81 Yeh HI, Lai YJ, Chang HM, Ko YS, Severs NJ, Tsai CH: Multiple connexin expression in regenerating arterial endothelial gap junctions. Arterioscler Thromb Vasc Biol 2000;20:1753-1762.

-82 Gonzalez JP, Ramachandran J, Xie LH, Contreras JE, Fraidenraich D: Selective Connexin43 Inhibition Prevents Isoproterenol-Induced Arrhythmias and Lethality in Muscular Dystrophy Mice. Sci Rep 2015;5:13490.

-83 Hawat G, Benderdour M, Rousseau G, Baroudi G: Connexin 43 mimetic peptide Gap26 confers protection to intact heart against myocardial ischemia injury. Pflugers Arch 2010;460:583-592.

-84 O'Carroll SJ, Alkadhi M, Nicholson LF, Green CR: Connexin 43 mimetic peptides reduce swelling, astrogliosis, and neuronal cell death after spinal cord injury. Cell Commun Adhes 2008;15:27-42.

85 Wang N, De Vuyst E, Ponsaerts R, Boengler K, Palacios-Prado N, Wauman J, Lai CP, De Bock M, Decrock E, Bol M, Vinken M, Rogiers V, Tavernier J, Evans WH, Naus CC, Bukauskas FF, Sipido KR, Heusch G, Schulz R, Bultynck G, Leybaert L: Selective inhibition of Cx43 hemichannels by Gap19 and its impact on myocardial ischemia/reperfusion injury. Basic Res Cardiol 2013;108:309. 